\title{
PREGNANCY AND LABOUR IN THE PARAPLEGIC
}

\author{
By D. N. S. Robertson, M.B., Ch.B.(Edin), F.R.C.O.G. \\ Stoke Mandeville Hospital
}

As a result of the co-operation of the National Spinal Injuries Centre and the department of obstetrics and gynaecology at Stoke Mandeville Hospital I am able to report this series of cases.

During the 20 years, I952-I972, 26 paraplegic women had 39 babies. The ante-natal care and labour were conducted under the personal supervision of Sir Ludwig Guttmann and more recently Dr. Jack Walsh and myself. So close was that co-operation that one of these babies now goes through life with the advantage, or otherwise, of bearing the christian names of Sir Ludwig and myself.

Cause of the Paraplegia. Twenty women were traumatic paraplegics, the highest lesion of which was at the level of cervical 4 and 5. Only one woman, in a road traffic accident at the 36th week, causing a fracture dislocation at thoracic 3, sustained her injury during pregnancy. Four women were paralysed as a result of disease of the spinal cord. Poliomyelitis was the cause of paralysis in two patients.

Foetal Results. Five babies were stillborn. This is a high stillbirth rate, 78 per Ioco births, compared with the national figure for England in 1970 of I 3 per Iooo births. There were no neo-natal deaths; no cases of congenital malformation and there were no twins or triplets.

The health, vigour and the birth weights of the 34 live babies did not differ from the babies of normal women. They all thrived on either breast or artificial feeding.

Method of Delivery. Twenty one babies were delivered normally. Fifteen were delivered by obstetric forceps. This is a high rate but it was necessary because the muscles responsible for the expulsive efforts of the second stage of labour were paralysed. Severe hypertension during the second stage of labour in three patients indicated shortening the second stage by a forceps delivery. Three babies were delivered by Caesarean Section.

Although the Caesararian rate is high, the indications to deliver the three patients by this route were obstetrical and not because the patients were paraplegic. The first patient had a Caesarean Section because she was a severe diabetic, and the second had a central placenta praevia. The third patient had a permanent suprapubic cystotomy and had had a previous abdominal hysterotomy; the breech was presenting and it was deemed wiser to deliver her by Caesarean Section.

I do firmly believe that paraplegia per se is not an indication for delivery by Caesarean Section.

The Innervation of the Uterus and Sensations during Labour. For over a century it has been known that the uterus has the capacity to contract normally in labour when the nerve supply has been severed. This was shown by Sir James 
Young Simpson in 1872 who found normal parturition in pigs after removal of the thoracic and lumbar cord.

Hof bauer in 1929 believed a mechanism existed in the uterus analogous to the Purkinje or conductive system in the heart.

Chassar Moir, addressing the IIth British Congress of Obstetrics and Gynaecology, Edinburgh, I939 on the Nature of the pain of labour gave his views on the pathways by which pain sensation is transmitted from the uterus. He stated, 'impulses from the uterus which give rise to pain pass by way of the autonomic nerves to the central nervous system. The sympathetic division is chiefly concerned with transference of such stimuli, but according to some authorities the parasympathetic nerves may also contribute afferent fibres to the uterus. In the case of the former the pathway is chiefly by way of the pre-sacral plexus to the spinal cord in the Ioth thoracic or the Ist and possibly 2nd or even the 3rd lumbar segments.'

Our experience with traumatic paraplegics where the cord was divided above the Ioth thoracic segment followed precisely that pattern in labour. All the patients had painless labours and normal polarised contractions, which is one of the few advantages of traumatic paraplegic women.

It was almost impossible to judge the onset of labour from the traumatic paraplegic's subjective sensations. A minority of patients, those with high lesions, experienced headache, sweating, flushing and pylo-erection of non-paralysed areas during a uterine contraction. A sharp, sometimes severe, rise in the B.P. not uncommonly accompanied these symptoms. This phenomenon has probably the same mechanism as described by Guttmann and Whitteridge (1947), when the urinary bladder is destended.

Patients whose paraplegia was caused by damage to the spinal cord due to disease, experienced pain sensations during a uterine contraction, and in addition, marked muscle spasm and ankle clonus, making labour unpleasant and distressing.

Paralytic anterior poliomyelitis causing paraplegia did not affect pain sensations of labour. As the name implies, anterior poliomyelitis damages the anterior horns of the spinal cord and the sensory pathways remain undamaged.

The Causes of the Stillbirths. Two babies died of anoxia, two died in utero at the 34th week of pregnancy as a result of maternal hyperpyrexia due to an acute pyelitis. The fifth stillbirth occurred to a patient who went into labour with a breech presentation at the $35^{\text {th }}$ week of pregnancy. She was at home and no help was at hand. On arrival home from work her husband discovered his wife with the body of the baby delivered some hours and the head still undelivered. The baby was dead.

Although the numbers are small I think there may be some significance in the two stillbirths caused by anoxia. One case occurred in a patient who was involved in a road traffic accident at the 36 th week of pregnancy and fractured her spine at the level of thoracic 3. Five days after her accident, labour commenced while the patient was still in the intensive care unit. Although the staff are highly trained to care for a paraplegic patient they are not experienced in caring for them in labour. The onset of labour was not recognized and it was only when the baby's head appeared at the vulva that the imminence of the birth was apparent. The foetal heart could not be heard although it had been clearly audible i 8 hours previously.

The baby was stillborn and the cause of death was judged to be severe anoxia 
due to placental insufficiency. The patient did have radiological examination of the spine after the accident.

The second stillbirth caused by anoxia occurred when a patient was in the second stage of labour for too long, one and a half hours. At that time the doctors on duty were performing an emergency Caesarean Section, and the labour ward sister was over-optimistic that a spontaneous birth was near. The foetal heart suddenly stopped, delivery was completed by forceps, and all efforts to resuscitate the baby failed. The cause of death was anoxia due to placental insufficiency.

Recently an efficient and simple test for placental efficiency has been placed in our hands, called the oestriol test for placental function and is well described and explained by Turnbull (197I). The test involves collecting a 24-hour urine specimen of which the oestriol is laboratory extracted, this can be carried out in a matter of hours. A series of these tests should be carried out at the $34^{\text {th }}$ to the 36 th week of pregnancy.

I feel this test is such a valuable addition to our knowledge of the efficiency of the placenta that all pregnant paraplegic women should have an oestriol test performed.

In giving advice to a paralysed woman on the wisdom of embarking on pregnancy the complication of renal tract infection must rank high in our deliberations. It is essential that renal function tests which include an intravenous pyelogram be considered. Infection of the tract which has resisted treatment need not make us advise against pregnancy provided renal function is unimpaired, but there is of course the risk of an exacerbation during pregnancy. Two cases in our series did have an acute flare-up sufficiently severe to cause intra-uterine death of the babies at the 32 nd and the $34^{\text {th }}$ week of pregnancy.

Continuous treatment with antibiotics was not employed during pregnancy in the 39 pregnancies in our series. However, an increase of pus cells or a heavy culture of organisms should indicate a course of the appropriate antibiotics. No case in our series had clinical evidence of deterioration of renal function following pregnancy.

We were fortunate in this series to have no deaths of live-born babies and no cases of congenital malformation.

Göller and Paeslack (1970-7I) reported two malformed babies in six babies born to paraplegic patients. The mothers of the two malformed babies became paraplegic at the $4^{\text {th }}$ to 5 th months of their pregnancy and X-ray examinations were necessary to diagnose the extent of trauma to the spine. As commented by Göller and Paeslack, the X-ray examinations were carried out so early in pregnancy they were likely to have damaged the immature foetal tissues.

This hazard to the foetus at an early stage of pregnancy would seem, at the moment, to be unavoidable as the interests of the mother are paramount. Screening of the pelvis from X-radiation during exposures may offer the foetus some protection but the dose of $\mathrm{X}$-rays necessary for radiological investigation of the spinal column is so high that scatter cannot fail to reach the foetus. The earlier the stage of pregnancy, the more susceptible to X-rays are the immature foetal tissues. Later in pregnancy the foetal gonads are liable to damage.

The Onset of Premature Labour. If the traumatic paraplegic has a lesion above Tio, the onset of premature labour is more likely than the usual hazard. The patient may be unaware that labour has commenced and premature delivery 
can occur in unfavourable surroundings without aid being at hand. I referred earlier to the patient who went into labour alone at home at the $35^{\text {th }}$ week of pregnancy, with a breech presentation. A further patient who was in hospital at the $34^{\text {th }}$ week of pregnancy gave birth, unaware labour had started. She rang her bell at 4.00 a.m. to tell the nurse she could hear a baby crying. When the nurse pulled back the bedclothes there was no doubt which baby was crying.

Therefore at each ante-natal examination after the 28th week the cervix is examined. If there is dilatation, the patient is admitted to hospital (Paraplegic patients are always admitted to hospital by the 32nd week of their pregnancy.)

Pre-eclamptic Toxaemia. The blood pressure of the traumatic paraplegic patient is more than usually labile. Distension of an abdominal viscus and uterine contractions can produce an abnormal B.P. rise. One therefore would have expected the incidence of pre-eclamptic toxaemia to be higher in this group of patients than among normal women. Yet, the reverse was true, there were no cases which exhibited any signs of pre-eclamptic toxaemia. In a larger series, however, pre-eclamptic toxaemia can be expected to occur. Should the B.P. be already raised due to pre-eclamptic toxaemia the hypertensive response provoked by uterine contractions could initiate an intracranial vascular accident or eclamptic convulsions.

The management of labour of the high traumatic lesion patient with preeclamptic toxaemia should include elimination of the second stage of labour by forceps delivery or Caesarean Section. This may have to be considered even before labour has started.

Breast Feeding. All the patients in our series successfully breast-fed their babies. They all, including the tetraplegic patient, had a normal 'let-down' phenomenon during suckling.

Prior to 1945 there was little hope offered to the unfortunate individual who became a paraplegic, and little was known of the measures necessary to restore them, other than being permanently bedridden. During the decade of I 940 to 1950 only two cases of pregnancy in paralysed women were reported in the world literature. In Great Britain, under the inspiration and direction of Sir Ludwig Guttmann, the treatment and facilities offered to these people has transformed their outlook on life: marriage is not discouraged when the door of opportunity opens and pregnancy is not banned merely because they are paraplegics.

Acknowledgment. I wish to pay a tribute to the work of all members of the International Medical Society of Paraplegia and in particular to my former colleague, Sir Ludwig Guttmann.

\section{REFERENCES}

MoIR, J. C. (1939). F. Obstet. E Gynaec. Brit. Emp. 46, 409.

GutTMANN, L. \& WhitTERIDGe (1947). Brain, 70, 36I.

Göller, H. \& PAeslak, V. (I970-7I). Paraplegia, 8, I6I.

Turnbuli., A. C. (I97I). Brit. F. Hosp. Med. 27. 